\title{
Optimisation of accelerated ageing of grape marc distillate on a micro-scale process using a Box-Benhken design: influence of oak origin, fragment size and toast level on the composition of the final product
}

\author{
R. RODRÍGUEZ-SOLANA ${ }^{1,2}$, S. RODRÍGUEZ-FREIGEDO',2, J.M. SALGADO ${ }^{3}$, J.M. DOMÍNGUEZ ${ }^{1,2}$ and \\ S. CORTÉS-DIÉGUEZ ${ }^{1,2}$
}

\author{
' Department of Chemical Engineering, Sciences Faculty, University of Vigo (Campus Ourense), 32004 Ourense, Spain; \\ ${ }^{2}$ Laboratory of Agro-food Biotechnology, CITI-Tecnópole, Ourense, Spain; ${ }^{3}$ CEB-Centre of Biological Engineering, University \\ of Minho, Campus de Gualtar, 47 I0-057 Braga, Portugal \\ Corresponding author: Dr Sandra Cortés-Diéguez, email smcortes@uvigo.es
}

\begin{abstract}
Background and Aims: The ageing process, in wooden barrels, is used to improve the sensory quality of wines and distillates. This process, however, is costly, often leading to an alternative strategy of using wood fragments. The main aim of this work was to evaluate the influence of size, toast level and origin of the oak fragments on the composition of grape marc distillates.

Methods and Results: The accelerated ageing process of grape marc distillate was optimised with a Box-Benhken experimental design. Five dependent variables were evaluated: the concentration of vanillin, whiskey lactone and phenolic substances, the antioxidant activity and the colour parameters to determine the influence of the independent variables: concentration of oak fragments, proportion of ethanol in Galician grape marc distillate (Orujo) and the time of maceration. The concentration of oak fragments was the variable with the greatest effect on the dependent variables evaluated, except for whiskey lactone. The optimal conditions obtained were applied in 11 experimental accelerated ageing processes to study the influence of size, toast level and origin of the oak fragments on the parameters previously mentioned.

Conclusions: The best results were obtained with the smaller fragment size (granular) from Quercus petraea with medium toast level. The contact time did not significantly influence the parameters evaluated.

Significance of the Study: This study, performed at a micro-scale, determined the optimum conditions for greater extraction of compounds from oak with beneficial characteristics: volatile compounds with positive notes, vanillin and whiskey lactone, and the phenolic substances with antioxidant properties. This option allows producers to reduce considerably the cost of the process.
\end{abstract}

Keywords: aged distillate, antioxidant activity, Box-Benhken, oak fragments (granules, chips), phenolic substances, volatiles

\section{Introduction}

Aged grape marc distillate, or aged Orujo, is a type of spirit elaborated in the north-west of Spain (Galicia). For at least 1 year, fresh distillate remains in oak barrels, without mixture or in combination with other distillates, only with those prepared at the same time of distillation. The regulations also establish that the capacity of the container cannot exceed the 1000 L (Official Diary from Galicia 2012). Quercus robur is the species of oak wood most employed; however, other species of oak have been also used, resulting in a good quality product (Rodríguez-Solana et al. 2012).

The ageing process is used to improve the sensory attributes of the fresh distillate (Léauté et al. 1998, Caldeira et al. 2002, 2006, 2010, Rodríguez-Solana et al. 2012). The use of alternatives to the traditional barrels (oak wood fragments) is a rapid and economical method of ageing treatment (Fan et al. 2006). This practice was approved by the Organisation Internationale de la Vigne et du Vin (Organisation Internationale de la Vigne et du Vin 2005) and is allowed in several countries of the European Union, including Spain for the elaboration of wines (European Commission 2005).

Nowadays, there is no legislation applying to the ageing of spirits in contact with oak wood fragments, and as a result, research on the accelerated ageing of distillates is scarce. There is some work on brandy aged in contact with wood fragments, on cider brandy, on aged rum and on Brandy de Jerez (Quesada Granados et al. 2002, Canas et al. 2009, 2013, Caldeira et al. 2010, Cruz et al. 2013, Rodríguez Madrera et al. 2013, Schwarz et al. 2014).

Although different factors can influence the composition of the final product, the most important is the botanical and geographical origin of the oak. The species used most often are American oak (Quercus alba) and French oak (Q. robur and Q. petraea) (Pérez-Coello et al. 1998, Arapitsas et al. 2004). Other factors are also important during accelerated ageing: the oak fragment size [chips, granules (chips milled without dust), beans, stavettes and tank staves], the amount of applied wood (between 0.5 and $5 \mathrm{~g} / \mathrm{L}$ ) and the toasting level (light, medium and high) (Arapitsas et al. 2004, Caldeira et al. 2010).

Of the compounds extracted from oak, vanillin is one of the main volatile compounds with a significant effect on aroma composition because of its low olfactory threshold (about $320 \mu \mathrm{g} / \mathrm{L})$ contributing aromatic notes of vanilla to oak-aged alcoholic beverages (Caldeira et al. 2008, Jánacová et al. 2008). Vanillin (4-hydroxy-3-methoxybenzaldehyde) is a low 
molecular mass compound, a direct product of lignin oxidative degradation (Gimenez Martinez et al. 1996). Vanillin is normally present in green wood, but its concentration can be increased by seasoning and toasting (Pérez-Prieto et al. 2002).

Box-Benhken design has been used to optimise the conditions for the elaboration of products, such as apple wine and cider vinegar (Zhang et al. 2011, Wang and Dai 2012). This design allows, in a few experiments, the optimisation of the independent variables (alcohol content, oak quantity and time of maceration) to maximise the values of the parameters under study [volatile compounds characteristic of oak (whiskey lactone and vanillin), concentration of phenolic substances, colour parameters and antioxidant capacity] during the ageing process (Rodríguez-Solana et al. 2014a,b).

In the present work, we optimised the ageing process of Orujo with French, medium toasted oak chips with the Box-Benhken design. Such an experimental design has been applied to the optimisation of systems for the accelerated solvent extraction and supercritical fluid extraction (Rodríguez-Solana et al. 2014b) of fennel essential oil (Rodríguez-Solana et al. 2014a) and in the optimisation for the elaboration of different beverages (Zhang et al. 2011, Wang and Dai 2012). The results obtained will assist industry because this practice improves the final product quickly, knowing which variables have more influence in the ageing process when compared with that of traditional oak barrels.

The independent variables of the design were the alcohol concentration of the young distillate, the quantity of oak wood and the time of ageing, because these can influence the kinetics of extraction, oxidation and diffusion of compounds extracted from the oak wood. The last two variables were studied by Canas et al. (2009), demonstrating their influence on the composition of the final product. The dependent variable evaluated with the design was mainly the concentration of vanillin and whiskey lactone because of their positive aroma attributes, but other variables were also evaluated to determine the influence of the independent variables on the composition of the final product: the concentration of phenolic substances and colour parameters (intensity and hue).

The optimised independent variables were finally applied in 11 experimental elaborations to evaluate the importance of other parameters to the composition of the aged distillate: the influence of the botanical and geographical origin [American (Q.alba) and French oak (Q.petraea)], the oak wood fragment size (chips and granules) and the toast level (untoasted, light, medium and high). These experiments were carried out step by step.

\section{Materials and methods}

Raw materials: oak wood fragments and grape marc distillate Chips and granules of French (Q.petraea) and American (Q. alba) oak wood were provided by Laffort (Gipuzkoa, Spain). The characteristics of the oak wood used in the study were the following: French oak with four levels of toasting on chips (C) and granules (G) [untoasted (FCU and FGU), light (FCL and FGL), medium (FCM and FGM) and heavy (FCH and $\mathrm{FGH}$ )]; American oak with a medium level of toast on granules (AGM) and chips (ACM) and finally a mixture of the French and American oak with medium level of toast on granules (MGM) (Table S1).

The grape marc distillate under the name of the Geographical Indication Spirit of Galicia was provided by a local winery whose distillate is produced according to the guidelines of the Regulatory Board (Official Diary from Galicia 2012).

The Folin-Ciocalteu and 2,2-diphenyl-1-picrylhydrazyl (DPPH) reagents, absolute ethanol, 3,4,5-trihydroxybenzoic acid (gallic acid) and ( \pm )-5-butyl-4-methyldihydro-2(3H)furanone (whiskey lactone) were purchased from SigmaAldrich (Steinheim, Germany). 4-Hydroxy-3-methoxybenzaldehyde (vanillin) was purchased from Fluka (Steinheim, Germany).

\section{Elaboration of the aged distillate}

Approximately $6.5 \mathrm{~L}$ of distillate was necessary for the preparation of the 15 experiments (with duplicates) of the BoxBenhken design. For the Box-Benhken design, samples of spirit of variable ethanol concentration $(\% \quad v / v)$ were prepared with the starting distillate $(70 \%)$ diluted to $55 \%$ and $40 \%$ with distilled water. The ethanol concentration was measured with a Gay Lussac volume alcoholmeter. For the design of the experiment, 0.6, 1.8 and $3 \mathrm{~g}$ of oak chips added to the distillate $(120 \mathrm{~mL})$, yielding a chip concentration of 5,15 and $25 \mathrm{~g} / \mathrm{L}$, respectively. The headspace of the opaque bottles was minimised with glass beads; the bottles were stored in the dark. Macerates were filtered under vacuum after 2, 4 and 6 weeks, and the filtered distillates were maintained at $-40^{\circ} \mathrm{C}$ in the dark to avoid change to their composition.

For the study of the influence of other characteristics of the wood (the geographical region of the oak, the size of the oak fragments and the toast level), the optimal conditions of alcohol concentration, quantity of wood and time of maceration obtained in the Box-Benhken design were applied to American and French chips and granules of different toast level in experiments carried out step by step.

\section{Determination of the concentration of phenolic substances}

Two methods were used to monitor the phenolic substances in the spirits, the concentration of phenolic substances (PS) and the phenolic substances index (PSI). Phenolic substances are mainly analysed by PS using the Folin-Ciocalteu reagent (Singleton and Rossi 1965, Singleton et al. 1998), which are reduced to oxidise phenols forming a blue colour, which can be measured at an absorbance of $750 \mathrm{~nm}$. The PSI is another method widely used because it is simple, fast and reliable. It is a faster method than the Folin-Ciocalteu method, because the absorbance at $280 \mathrm{~nm}$ of the samples is directly related to the extractable phenolic substances (at this wavelength the benzene nucleus, characteristic of phenolic substances has the maximum absorbance) (Engelhardt 2001, Yilmaz and Toledo 2006). For the determination of phenolic substances by the Folin-Ciocalteu method, a calibration curve with five points was established, and the results were expressed in milligram gallic acid equivalents per litre. All determinations were in duplicate and measured at $760 \mathrm{~nm}$ with a UV-VIS Cintra 6 spectrophotometer (GBC Scientific Equipment, Madrid, Spain). The PSI was determined by measuring the absorbance of each sample at $280 \mathrm{~nm}$ employing a $1 \mathrm{~cm}$ quartz cuvette (Ribéreau-Gayon 1970). The PSI was determined with Equation 1:

PSI $=\mathrm{A}_{280 \mathrm{~nm}} *$ dilution factor

\section{Colour parameters: colour intensity and hue}

Colour intensity and hue were measured by the absorbance of undiluted samples at a wavelength of $420 \mathrm{~nm}$ (yellow), $520 \mathrm{~nm}$ (red) and $620 \mathrm{~nm}$ (violet) in a spectrophotometer 
employing optical quartz, $1 \mathrm{~mm}$ path length cuvettes. The equations for the colour intensity (Equation 2) and hue (Equation 3) [which is obtained according to Glories (1984)] are as follows:

colour intensity $=\mathrm{A}_{420 \mathrm{~nm}}+\mathrm{A}_{520 \mathrm{~nm}}+\mathrm{A}_{620 \mathrm{~nm}}$

hue $=\mathrm{A}_{420 \mathrm{~nm}} / \mathrm{A}_{520 \mathrm{~nm}}$

\section{Antioxidant capacity}

The antioxidant capacity was determined in duplicate using the DPPH method described by Rawson et al. (2013), using ethanol as the solvent in order to simulate as much as possible the sample matrix. The results were expressed as the inhibition of free radicals by DPPH expressed as a proportion [I (\%)] which is calculated with the following equation:

$\mathrm{I}(\%)=\left(\mathrm{A}_{\text {blank }}-\mathrm{A}_{\text {sample }} / \mathrm{A}_{\text {blank }}\right) \mathrm{x} 100$

where $A_{\text {blank }}$ is the absorbance of the control (all reagents except the sample) and $\mathrm{A}_{\text {sample }}$ is the absorbance of the sample.

\section{Experimental design}

For optimisation of the critical factors in the elaboration of accelerated ageing of beverages using oak chips, the following variables were chosen: concentration of chips, ageing time and ethanol concentration $[\%(\mathrm{v} / \mathrm{v})]$ in the young distillate, using a Box-Behnken experimental design. This design is a response surface methodology that studies the effect of the chosen variables and their interactions. The three independent variables studied and their optimised ranges for chips of the botanical species Q.petraea and medium toasted are the following: the concentration of chips $\left(x_{1}\right)$ with a minimum value $(-1)$ of $5 \mathrm{~g} / \mathrm{L}$, centre value $(0)$ of $15 \mathrm{~g} / \mathrm{L}$ and maximum (1) of $25 \mathrm{~g} / \mathrm{L}$; the time $\left(x_{2}\right)$ values: minimum $(-1)$ of 2 weeks, central $(0), 4$ weeks and maximum value (1) of 6 weeks; and the ethanol concentration $\left(x_{3}\right)$, with a minimum value of $(-1) 40 \% \mathrm{v} / \mathrm{v}$, middle $(0) 55 \% \mathrm{v} / \mathrm{v}$ and maximum (1) 70\% v/v (Table S2). Box-Behnken design with three factors at three levels $(-1,0$ and +1$)$ was undertaken with three centre points $(0,0$ and 0$)$ in a set of 15 experiments, and the three replicates of centre point were used for estimation of the pure error. For statistical calculations, the independent variables were coded as $\mathrm{x}_{1}$ (coded concentration of chips), $x_{2}$ (coded time) and $x_{3}$ (coded \% alcohol).

The dependent variables were the following: concentration of PS; PSI; the phenolic substances, vanillin and whiskey lactone; antioxidant capacity; and colour parameters, colour intensity and hue. The experimental data were evaluated by response surface methodology using Statistica 5.0 software (Statsoft, Tulsa, OK, USA). The effect of each independent variable on the response was fitted by polynomial quadratic equations, which include linear, interaction and quadratic terms (Equation 5):

$$
\begin{aligned}
y= & b_{0}+b_{1} x_{1}+b_{2} x_{2}+b_{3} x_{3}+b_{12} x_{1} x_{2}+b_{13} x_{1} x_{3} \\
& +b_{23} x_{2} x_{3}+b_{11} x_{1}{ }^{2}+b_{22} x_{2}{ }^{2}+b_{33} x_{3}{ }^{2}
\end{aligned}
$$

where $y$ is the predicted response, $\mathrm{b}_{0}$ is the model constant, $\mathrm{x}_{1}$, $x_{2}$ and $x_{3}$ are independent variables (coded), $b_{1}, b_{2}$ and $b_{3}$ are linear coefficient, $b_{12}, b_{13}$ and $b_{23}$ are cross product coefficients and $b_{11}, b_{22}$ and $b_{33}$ are the quadratic coefficients. Dependent variables were optimised using an application of EXCEL 2007 (Solver, Microsoft, Redmond, WA, USA).

\section{Quantification of vanillin and whiskey lactone by GC-flame ionisation detection}

The concentration of vanillin and whiskey lactone of the aged distillates was determined with an Agilent 7890A GC equipped with flame ionisation detector. The column was an HP-INNOWax [polyethylene glycol (PEG) $60 \mathrm{~m} \times 0.25 \mathrm{~mm}$ i.d. $\times 0.25 \mu \mathrm{m}$ film thickness] (Agilent, Cheadle, England) . Samples $(1 \mu \mathrm{L})$ were injected in split mode $(10: 1)$. The oven temperature was programed as follows: $60^{\circ} \mathrm{C}$ during $15 \mathrm{~min}$ then 60 to $230^{\circ} \mathrm{C}$ at $3^{\circ} \mathrm{C} / \mathrm{min}$. Injector temperature was $250^{\circ} \mathrm{C}$ and that of the detector $260^{\circ} \mathrm{C}$. The flow of $\mathrm{H}_{2}$ was $1 \mathrm{~mL} / \mathrm{min}$.

An external calibration curve of five points was prepared in ethanol with the concentration of vanillin between 1 and $30 \mathrm{mg} / \mathrm{L}$ with good linearity, $\mathrm{R}^{2} 0.9994$ and with the concentration of whiskey lactone between $\mathrm{l}$ and $10 \mathrm{mg} / \mathrm{L}$ and $\mathrm{R}^{2} 0.9948$

\section{Statistical procedures}

The results obtained were analysed using XLstat-Pro (Addinsoft, Paris, France). One-way ANOVA was applied to establish whether a significant difference $(P<0.05)$ existed between the values obtained for the mean value of each parameter in the experimental samples analysed. The multiple range test (Fisher's least significant difference method) was applied to confirm the results obtained. Pearson's correlations between all parameters evaluated were also calculated. Principal component analysis (PCA) was applied to attempt the separation of the different experimental accelerated ageing processes because of the influence of the characteristics of wood (oak origin, fragment size and toast level) on the parameters evaluated (vanillin, colour parameters, phenolic substances and antioxidant capacity).

\section{Results and discussion}

Optimisation of the accelerated ageing of grape marc distillate: Box-Benhken design

The compounds of importance to the sensory properties of the aged grape marc distillates, vanillin (with vanilla notes) and whiskey lactone (with coconut notes) (Lee et al. 2000), the concentration of phenolic substances, colour parameters and antioxidant capacity were analysed with a Box-Behnken experimental design using medium toasted, French oak chips to evaluate the effect of oak fragments during the accelerated ageing of the final product.

This design offers the opportunity to determine the optimal values of the independent variables by establishing the relationship of these variables and the predicted responses. Three independent variables important to the elaboration of oak chip macerates were studied: concentration of oak $\left(\mathrm{X}_{1}\right)$, time $\left(\mathrm{X}_{2}\right)$ and \% alcohol $\left(\mathrm{X}_{3}\right)$ at three levels. Table 1 shows the design matrix of the coded variables together with the observed and predicted values by the model of dependent variables. Results showed that the value of experimental results and predicted values were similar except for the concentration of phenolic substances.

Table 2 displays regression coefficients of each dependent variable that allowed regression equations to be obtained for each dependent variable studied as a function of the concentration of chips, time and \% ethanol in linear and quadratic form and lineal interaction between variables. The determination coefficient $\left(\mathrm{R}^{2}\right)$ for principal components responses ranged from 0.9346 to 0.9855 , indicating a high correlation between observed and predicted values; the concentration of phenolic substances response had a lower $\mathrm{R}^{2}$ of 0.8850 . The values of 


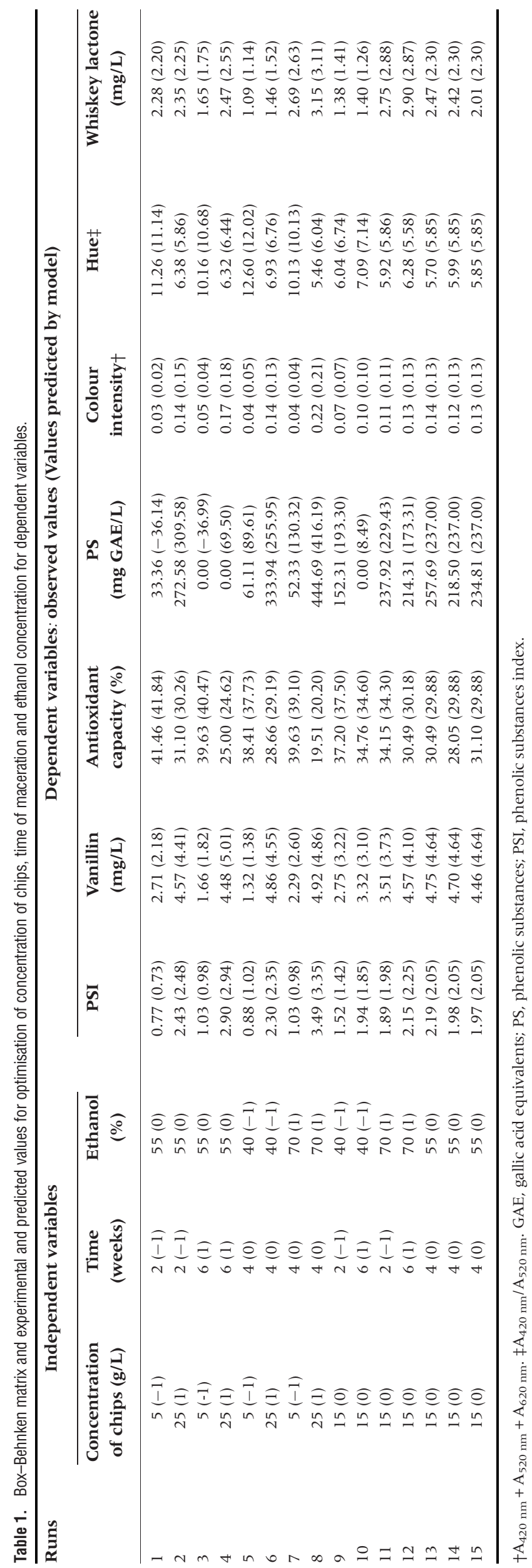

adjusted $\mathrm{R}^{2}$ were from 0.8170 to 0.9600 , confirming the significance of the models, except for the concentration of phenolic substances response where the adjusted $\mathrm{R}^{2}$ was 0.6781 . Thus, the model can predict the results of these parameters with good precision allowing the selection the more suitable conditions of elaboration.

Figure la-g (Pareto chart) shows the relative importance of the effect that each independent variable and the interactions among them have on the dependent variable, as well as those terms that are significant at $95 \%$. For all the dependent variables considered, the concentration of chips had a higher effect except for the whiskey lactone concentration in which the linear term of ethanol $[\%(\mathrm{v} / \mathrm{v})]$ showed greater influence. Figure 2a-g shows the response surface models, which predict the result of dependent variables by three-dimensional (3D) responses. These $3 \mathrm{D}$ responses were obtained using Equation 5 for each dependent variable. In each 3D surface plot, one independent variable (with the lowest effect) was kept constant at medium level, while the other two independent variables varied in the selected range.

Concentration of phenolic substances. The highest PSI in the alcoholic beverages is related to the greater extraction/diffusion of the phenolic substances from wood (Cruz et al. 2013). The effect of the independent variables on PSI was evaluated (Figure la), and a positive and significant (at $90 \%$ ) effect of the concentration of chips and of ethanol was observed. A small increase in PSI, however, can be observed in experiments 1 and 3 (Table 1) from 0.77 to 1.03 after 2 and 6 weeks, respectively. The predicted maximum PSI was 3.41 with $25 \mathrm{~g} / \mathrm{L}$ of oak chips, 5.21 weeks and $70 \%$ ethanol.

All independent variables had a significant effect on the extraction of phenolic substances as measured by the FolinCiocalteu method, with the variable concentration of chips having a greater effect.

Whiskey lactone and vanillin. Whiskey lactone and vanillin were the compounds with important sensory properties extracted in the maceration process. Whiskey lactone is formed from lipids in oak wood during toasting, although it is also present in natural oak (Singleton 1995). Extraction time and concentration of chips had no significant effect on the extraction of whiskey lactone (Figure $1 \mathrm{~g}$ ). Pizarro et al. (2014) evaluated the effect of maceration time, chip concentration and other parameters during the maceration of red wines, and they observed that maceration time had no effect on the extraction of whiskey lactone, whereas other parameters, such as type of oak and toasting level, had a greater effect. The maximum concentration of whiskey lactone was obtained at the highest concentration of chips and ethanol content $(\% \mathrm{v} / \mathrm{v})$ (Figure $2 \mathrm{~g})$. Figure $2 \mathrm{~g}$ shows the strong effect of ethanol concentration in the extraction of whiskey lactone from the wood. At high concentration of chips $(25 \mathrm{~g} / \mathrm{L})$ and intermediate contact time (4 weeks), the concentration of whiskey lactone increased from 1.46 to $3.15 \mathrm{mg} / \mathrm{L}$ with increasing ethanol centration. The predicted maximum for whiskey lactone by the model was $3.24 \mathrm{mg} / \mathrm{L}$ under optimal conditions (Table 1).

Vanillin is produced by the thermal degradation of lignin during the toasting of wood although it is also present in natural wood (Cano-López et al. 2008). The Pareto chart of vanillin (Figure $\mathrm{lb}$ ) shows that the linear terms of concentration of chips and of ethanol and quadratic terms of concentration of chips, time and ethanol had a significant effect (at $95 \%$ ) on vanillin extraction. Results showed that chip 
Table 2. Regression coefficients, statistical parameters and optimal conditions for dependent variables.

\begin{tabular}{|c|c|c|c|c|c|c|c|}
\hline Coefficients & PSI & Vanillin & $\begin{array}{c}\text { Antioxidant } \\
\text { capacity }\end{array}$ & $\begin{array}{c}\text { Phenolic } \\
\text { substances }\end{array}$ & $\begin{array}{c}\text { Colour } \\
\text { intensity } \dagger\end{array}$ & Hue $\neq$ & $\begin{array}{l}\text { Whiskey } \\
\text { lactone }\end{array}$ \\
\hline$b_{0}$ & $2.04 * * *$ & $4.64^{* * *}$ & $29.88^{* * *}$ & $237.00^{* * *}$ & $0.13^{* * *}$ & $5.85 * * *$ & $2.30 * * *$ \\
\hline$b_{1}$ & $0.93^{* * *}$ & $1.36^{* * *}$ & $-6.86^{* * *}$ & $113.05^{* * *}$ & $0.06^{* * *}$ & $-2.38^{\star * *}$ & 0.21 \\
\hline$b_{11}$ & -0.11 & $-0.74^{* *}$ & 0.91 & $-44.31^{* *}$ & -0.01 & $2.57 * * *$ & -0.06 \\
\hline$b_{2}$ & $0.18^{* *}$ & 0.06 & $-1.75^{*}$ & $-60.23^{* *}$ & 0.01 & 0.03 & -0.04 \\
\hline$b_{22}$ & -0.16 & $-0.55^{* *}$ & $3.51^{*}$ & $-116.20^{* * *}$ & $-0.02 *$ & 0.12 & -0.05 \\
\hline$b_{3}$ & $0.24^{* *}$ & $0.38^{* *}$ & $-1.90^{*}$ & $50.24^{* *}$ & $0.02^{* *}$ & $-0.61^{* * *}$ & $0.77^{* *}$ \\
\hline$b_{33}$ & -0.01 & $-0.55^{* *}$ & 0.76 & $30.33^{*}$ & -0.01 & $0.37^{* *}$ & -0.14 \\
\hline$b_{12}$ & 0.05 & $0.24^{*}$ & -1.07 & $-59.80^{* *}$ & 0.00 & $0.26^{*}$ & 0.19 \\
\hline$b_{13}$ & $0.26^{* *}$ & $-0.23^{*}$ & $-2.59 *$ & $29.88^{*}$ & $0.02^{*}$ & $0.25^{*}$ & 0.02 \\
\hline$b_{23}$ & -0.04 & 0.12 & -0.30 & $32.17^{*}$ & -0.00 & -0.17 & 0.03 \\
\hline$r^{2}$ & 0.98 & 0.93 & 0.98 & 0.88 & 0.99 & 0.97 & 0.96 \\
\hline$r^{2 a d j}$ & 0.96 & 0.82 & 0.95 & 0.68 & 0.96 & 0.91 & 0.90 \\
\hline \multicolumn{8}{|l|}{ Optimal conditions } \\
\hline Chips concentration (g/L) & 25.00 & 24.40 & 5.00 & 25.00 & 25.00 & 5.00 & 25.00 \\
\hline Time (weeks) & 5.21 & 4.57 & 6.00 & 3.23 & 4.00 & 2.00 & 6.00 \\
\hline Ethanol (\%) & 70.00 & 57.72 & 70.00 & 70.00 & 70.00 & 40.00 & 70.00 \\
\hline
\end{tabular}

Significant $P$ values are indicated: ${ }^{*}, P<0.10 ; * *, P<0.05 ; * * *, P<0.01 . \mathrm{r}^{2}$, determination coefficient. $+\mathrm{A}_{420 \mathrm{~nm}}+\mathrm{A}_{520 \mathrm{~nm}}+\mathrm{A}_{620 \mathrm{~nm}} . \ddagger \mathrm{A}_{420 \mathrm{~nm}} / \mathrm{A}_{520 \mathrm{~nm}}$. adj, adjusted. PSI, phenolic substances index.

concentration had a clear positive effect, followed by ethanol concentration.

Antioxidant capacity. The antioxidant capacity (Figure lc) shows a negative effect of the concentration of chips, with significant effect at $95 \%$. As a result, a low concentration of chips favoured antioxidant capacity of the spirit. This antioxidant capacity is related to the amount of phenolic substances extracted from the oak wood (Jordão et al. 2012).

Colour parameters. Colour is a major attribute affecting the consumer perception of quality and can be used as a direct quality estimate in beverages and other foods. It can predict attributes such as over-processing and be used as a tool to follow the change of a product and to determine relationships with other food attributes, such as acceptance, visual colour and appearance (Granato and Masson 2010). Colour intensity and hue are parameters that can influence consumer decision; thus to be able to identify the maceration conditions that lead to colour intensity and hue accepted by consumers is of great interest. The model could predict the results of these parameters of varying concentration of chips, time and \% alcohol. The concentration of chips and of ethanol had a significant effect (at 95\%) on both parameters, positive in the case of colour intensity and negative for the hue value. In Figure $2 \mathrm{f}$, it can be seen that the maximum value of colour intensity was achieved at maximum concentration of chips and of ethanol being the maximum predicted value 0.22 . Figure $2 \mathrm{e}$ showed the evolution of hue with varying concentration of chips and of ethanol leading to an optimal region in the lower value of the concentration of chips. Results showed that the maximum value of hue predicted by the model was 12.20 .

\section{Comparison between oak fragment size, oak origin and toast level in the elaboration of accelerated aged distillate}

Once the optimisation process was carried out, the optimal values for the independent variables were applied to the accelerated ageing of distillate with different oak fragments.
For this study, on a micro-scale, the effect of oak fragment size, granules and chips, and oak origin, French oak, Q. petraea with different toast levels (untoasted, light, medium and high) and American oak, Q.alba with medium toast level and finally a mix of both types of oak with medium toast level were assayed (Figure S1).

The same parameters evaluated during the optimisation process have been measured in the 11 experiments of an accelerated ageing process. Results obtained are showed in Table 3.

Phenolic substances-PSI and PS. The consumption of food and beverages with high concentration of phenolic substances is correlated with reduced cardiovascular and neurodegenerative diseases and cancer mortality (Umar et al. 2003). This is possibly because of the biological effects of these compounds as antioxidants (Goldberg et al. 1999, Vinson et al. 2001, Priyadarsini et al. 2002, Sroka and Cisowski 2003).

In American oak, the smallest fragment (granules) provided the higher concentration of phenolic substances, and in general, the behaviour was similar to that of French oak. This may be due to the higher ratio between solvent and the smallest particle size (Jordão et al. 2012), where the surface in contact with the solvent is higher. The concentration of the phenolic substances was significantly higher in distillate aged in Q.petraea (almost twofold more) than distillate aged in Q.alba. These results agreed with those of Jordão et al. (2012) where they studied extracts of oak fragments of different size (between 2 and $8 \mathrm{~mm}$ ), with different toasting levels (light, medium and high) and different species of oak (Q.petraea and Q.alba). The toasting level did not follow a trend in the concentration of phenolic substances, because in French oak granules, the higher value was obtained at the untoasted and medium toasting level, but in French oak chips, the higher values were obtained with untoasted and high-toast chips. Soares et al. (2012) found that synthetic wine macerated with untoasted oak presented a value higher than that with medium and high-toasted oak. 

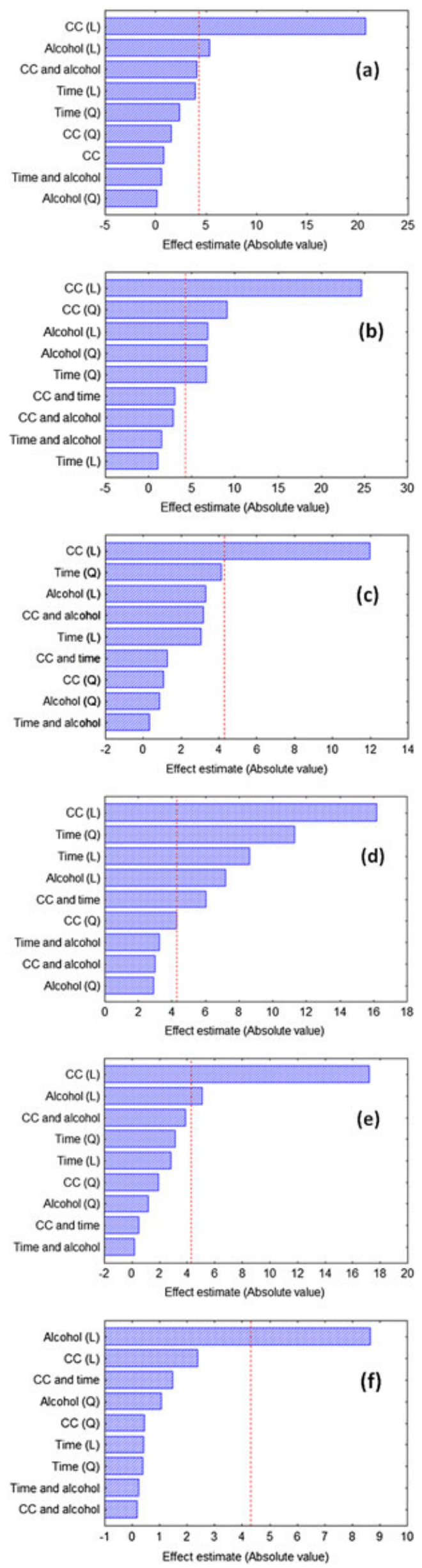

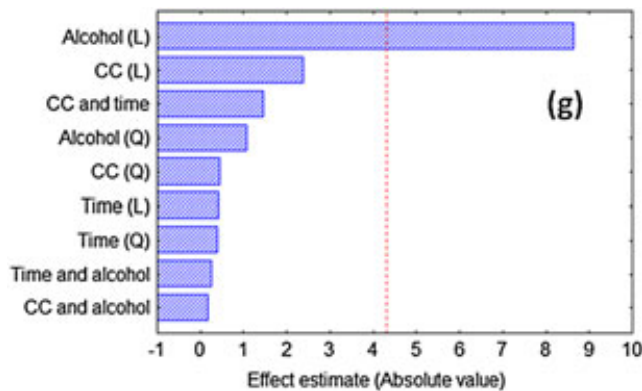

Figure 1. Pareto charts for (a) phenolic substances index; (b) vanillin; (c) antioxidant capacity; (d) phenolic substances; (e) colour intensity; (f) hue; and (g) whiskey lactone extracted from medium toast French oak chips as a linear $(\mathrm{L})$ or quadratic $(\mathrm{Q})$ function of the independent variables assayed [oak pieces concentration (CC), contact time and alcohol concentration]. The significance $P$ value $(0.05)$ is indicated by the red vertical dashed line.

Jordão et al. (2012) considered that these results may be due to the lack of homogeneity of the oak because it is a natural product; many companies have patented the toasting process and do not specify it in detail.

In contrast, Table 3 shows that, in general, the oak granules presented values of PSI significantly higher than that of oak chips. Between Q.petraea and Q.alba, the PSI values were always significantly higher in the distillate aged in the French oak. In all samples, except with granules, the PSI values increased with the toast level. These results are in agreement with PSI values obtained by Canas et al. (2002) with brandy aged in oak staves with light (9.62) and high (11.76) toast level.

Vanillin. Vanillin is one of the low molecular mass phenolic substances responsible for taste, aroma and flavour of alcoholic beverages aged in oak (Caldeira et al. 2008, Jánacová et al. 2008). This compound gives a vanilla aroma with a positive correlation with the overall quality of the aged spirit (Caldeira et al. 2010). It is a marker or ageing indicator because it can be measured during the ageing process and thus can be used to estimate the time required to age a distilled beverage (De Aquino et al. 2006). Moreover, vanillin is also present in natural wood, being adequate to study the behaviour of the different toasted oak fragments assayed in this research.

All experimental assays showed a concentration of vanillin significantly different, with higher values in spirit aged in contact with medium toast French oak granules. The behaviour of fragment size in Q.alba is the same as that in Q.petraea: oak granules provide significantly more vanillin than oak chips, because the size of oak chips may have a significant effect on the formation of vanillin during toasting (this compound is formed by thermal degradation of lignin during oak toasting). Small pieces are more combustible, and more vanillin is formed (until $5 \mathrm{~mm}$ in size where losses of vanillin occur by evaporation) (Bautista-Ortín et al. 2008). Similar results have been shown by Rodríguez Madrera et al. (2013) who studied different sizes of oak and found that between barrels and staves the quantity of vanillin is greater in cider brandy aged in contact with staves. Fernández de Simón et al. (2010) studied the difference between staves and chips in the ageing of red wine and found that in all cases the extraction was greater with chips.

The comparison of vanillin extraction between Q.petraea and Q.alba indicated that the French oak provides more vanillin than American oak (almost twofold more). Rodríguez Madrera et al. (2010) showed similar results for the concentration of vanillin in spirit aged in contact with medium toast 

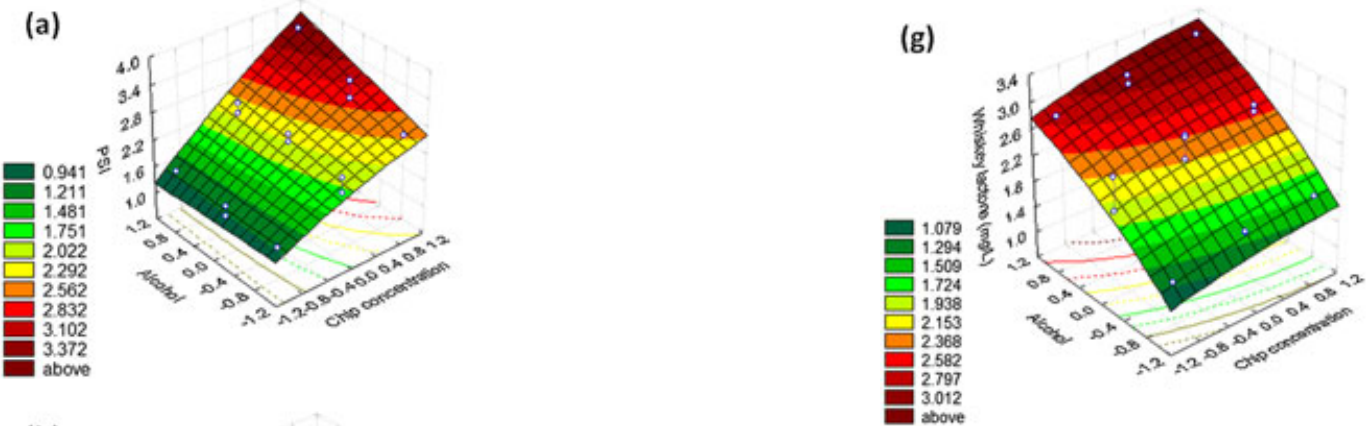

(b)

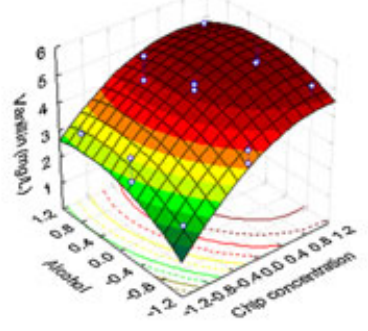

(c)

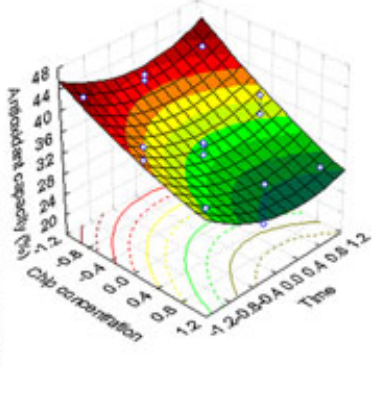

(d)

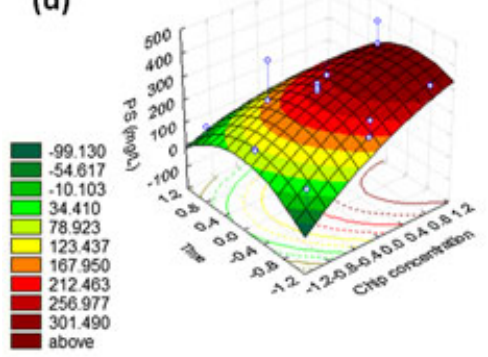

(e)
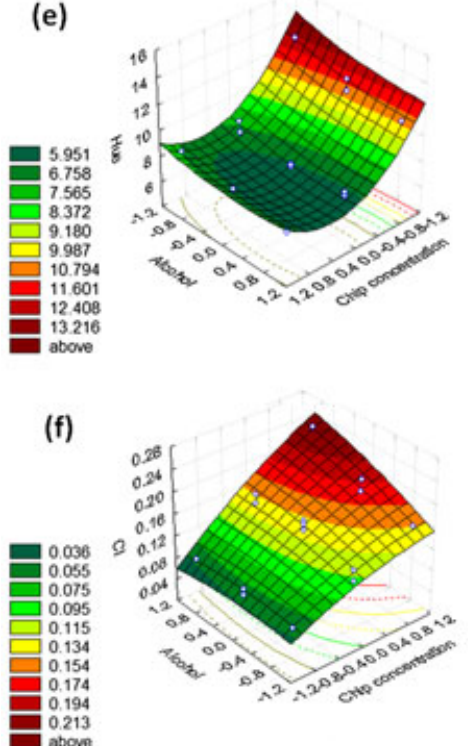

Figure 2. Response surface of (a) phenolic substances index (PSI); (b) vanillin; (c) antioxidant capacity; (d) phenolic substances (PS); (e) hue; (f) colour intensity $(\mathrm{Cl})$; and $(\mathrm{g})$ whiskey lactone extracted from oak as a function of concentration of oak chips, alcohol and contact time.

American oak chips $(4.19 \mathrm{mg} / \mathrm{L})$, but less for the spirit aged in medium toast French oak chips $(4.74 \mathrm{mg} / \mathrm{L})$. A later study on cider brandy by the same research group (Rodríguez Madrera et al. 2013), however, showed a similar concentration of vanillin for oaks of different origin [contact time 4 months: French $(3.4 \mathrm{mg} / \mathrm{L})$, American $(3.4 \mathrm{mg} / \mathrm{L})$ and Spanish $(3.6 \mathrm{mg} /$ L)], although the value for the American oak is similar to that of the present work. Other authors, Fan et al. (2006) obtained similar values in apple cider aged in contact with French and American chips $(0.27$ and $0.29 \mathrm{mg} / \mathrm{L}$, respectively).

When we evaluated the influence of the toast level, the concentration of vanillin in spirit in contact with Q.petraea granules (Table 3) increases with the toast level until medium toast, with similar behaviour for oak chips. This behaviour was similar for the ageing of red wine with staves and chips of Q.pyrenaica, but in this case, the quantity of vanillin continued to increase in the high level of toasted oak (Fernández de Simón et al. 2010).

In all experiments, the vanillin concentration is higher than the corresponding threshold value and for this reason contributes to the aroma of the aged distillates increasing its positive notes, despite the possible interaction effects between the other volatile compounds.

Antioxidant capacity. The interest in the measurement of antioxidants is due to these compounds being able to mitigate the activity of the free radicals responsible for several diseases, such as premature ageing, prostaglandin-mediated inflammatory processes and cancer (Combs 1991, Halliwell et al. 1992). Results for the antioxidant activity were similar between granules and chips, with the exception of medium toast French oak, which showed a value significantly higher for chips. Comparing the antioxidant activity value in the distillate aged in contact with French or American oak, results showed higher and similar values, both in granular or in chips presentation, in the case of American oak, while French oak showed lower and different values for both fragment macerations. In all cases, the antioxidant capacity declined with increasing toast level (Table 3), which contrasts with those of Canas et al. (2008) who found no significant difference in antioxidant activity of aged brandy with wood barrels of different toast levels (light, medium and high).

Colour parameters: hue and colour intensity. The hue value of the spirit for all experiments was similar, regardless of the characteristics of the oak fragment. Hue mean value in Q.petraea was 4.70 and in Q.alba 4.89 . These values were 
Table 3. Values of the parameters studied for the French and American oak granules and chips with optimal independent applied variables.

\begin{tabular}{|c|c|c|c|c|c|c|c|}
\hline \multicolumn{8}{|c|}{ Parameters of the optimised aged grape marc distillate } \\
\hline Code + & Species of oak & CI & Hue§ & $\begin{array}{l}\text { Antioxidant } \\
\text { capacity }(\%)\end{array}$ & PSI & PS (mg GAE/L) & $\begin{array}{c}\text { Vanillin } \\
(\mathrm{mg} / \mathrm{L})\end{array}$ \\
\hline MGM & Quercus petraea + Quercus alba & $0.18 \mathrm{C}$ & $4.79 \mathrm{a}, \mathrm{b}$ & $62.24 \mathrm{a}, \mathrm{b}$ & $3.45 \mathrm{c}, \mathrm{d}, \mathrm{e}$ & $714 \mathrm{~d}, \mathrm{e}$ & $8.62 \mathrm{~b}$ \\
\hline FGU & Q.petraea & $0.10 \mathrm{~d}, \mathrm{e}$ & $4.56 \mathrm{a}, \mathrm{b}$ & $75.51 \mathrm{a}$ & $4.45 \mathrm{~b}, \mathrm{c}, \mathrm{d}$ & $1209 a, b$ & $2.51 \mathrm{i}$ \\
\hline FGL & & $0.17 \mathrm{c}, \mathrm{d}$ & $4.64 \mathrm{a}, \mathrm{b}$ & $63.27 a, b$ & $4.98 \mathrm{a}, \mathrm{b}$ & 804 c,d & $5.09 \mathrm{f}$ \\
\hline FGM & & $0.38 \mathrm{a}$ & $4.39 \mathrm{~b}$ & $9.18 \mathrm{e}$ & $5.26 \mathrm{a}$ & 1289 a & $9.62 \mathrm{a}$ \\
\hline FGH & & $0.28 \mathrm{~b}$ & $4.84 \mathrm{a}, \mathrm{b}$ & $37.76 \mathrm{c}, \mathrm{d}$ & $4.03 \mathrm{~b}, \mathrm{c}$ & 954 b,c,d & $7.13 \mathrm{c}$ \\
\hline FCU & & $0.09 \mathrm{e}$ & $4.84 \mathrm{a}, \mathrm{b}$ & $75.51 \mathrm{a}$ & 3.79 b,c,d,e & $1089 a, b, c$ & $1.84 \mathrm{j}$ \\
\hline FCL & & $0.15 \mathrm{c}, \mathrm{d}, \mathrm{e}$ & $4.62 \mathrm{a}, \mathrm{b}$ & $73.47 \mathrm{a}, \mathrm{b}$ & $3.85 \mathrm{~b}, \mathrm{c}$ & $804 \mathrm{c}, \mathrm{d}$ & $4.35 \mathrm{~g}$ \\
\hline FCM & & $0.20 \mathrm{c}$ & $5.00 \mathrm{a}$ & $55.10 \mathrm{~b}, \mathrm{c}$ & $3.86 \mathrm{c}, \mathrm{d}, \mathrm{e}$ & 764 d,e & $6.66 \mathrm{~d}$ \\
\hline $\mathrm{FCH}$ & & $0.36 \mathrm{a}$ & $4.70 \mathrm{c}$ & $30.61 \mathrm{~d}$ & $5.36 \mathrm{a}, \mathrm{b}$ & $1029 \mathrm{c}, \mathrm{d}$ & $6.64 \mathrm{~d}$ \\
\hline AGM & Q.alba & $0.16 \mathrm{c}, \mathrm{d}, \mathrm{e}$ & $4.85 \mathrm{a}, \mathrm{b}$ & $63.27 a, b$ & $2.75 \mathrm{~d}, \mathrm{e}$ & 509 e,f & $5.54 \mathrm{e}$ \\
\hline ACM & & $0.13 \mathrm{c}, \mathrm{d}, \mathrm{e}$ & $4.93 \mathrm{a}, \mathrm{b}$ & $68.37 \mathrm{a}, \mathrm{b}$ & $2.52 \mathrm{e}$ & 419 e,f & $3.64 \mathrm{~h}$ \\
\hline
\end{tabular}

Values within a column with the same letter are not significantly different ( $P=0.05)$. †A, American oak; C, chips; F, French oak; G, granules; L, light toast; $\mathrm{M}$, medium toast; $\mathrm{H}$, heavy toast; $\mathrm{U}$, untoasted. $\ddagger$ MGM, medium toasted mixture of American and French oak granules. §Measured as $\mathrm{A}_{420} \mathrm{~nm} / \mathrm{A}_{520} \mathrm{~nm}$. CI, colour intensity measured as $\mathrm{A}_{420 \mathrm{~nm}}+\mathrm{A}_{520 \mathrm{~nm}}+\mathrm{A}_{620 \mathrm{~nm}}$. GAE, gallic acid equivalents; PS, phenolic substances; PSI, phenolic substances index.

similar to the mean values recorded in previous research of this group (data not shown) for distillates aged in barrels for 1-6 years: 5.26 for Q.petraea and 5.39 for Q.alba. These hue values reveal that there is no difference between oak fragments and barrels in aged spirits. The values of colour intensity, however, are much lower in spirits aged in contact with oak fragments (Table 3) than those obtained in barrels: 0.7 is the minimum value, and it was obtained in spirits aged in Q.alba barrels, while the maximum value was the 2.3 obtained in spirits aged in Q. robur (from Galicia) (Rodríguez-Solana et al. 2014c).

Among the spirits aged in contact with oak fragments, the American oak presented slightly greater hue. In general, French oak granules and chips show similar values of colour intensity except in the case of medium (higher value in oak chips) and high toast (higher value in oak granules). The colour intensity of spirit aged in contact with French and American oak is similar for both granules and chips. Compared with French oak fragments, American oak fragments always showed higher-colour intensity (almost twofold more). Colour intensity of spirit increases with toast level (until medium toast) for French oak granules and chips.

\section{Statistical analysis: Pearson correlation coefficients and principal component analysis}

Pearson correlation coefficients. Colour intensity was negatively correlated with the antioxidant capacity $(-0.975)$ and positively correlated with the PSI (0.617) and vanillin concentration (0.791) (Table 4). These results showed that a high-toast level implies the oxidative degradation of the phenolic substances from the oak decreasing the corresponding antioxidant capacity attributed to these compounds. Hue showed a negative correlation value with PSI $(-0.693)$ and PS $(-0.675)$, whereas it was positively correlated (0.379) with the antioxidant capacity. From the earlier results, it must be concluded that the presence of compounds with antioxidant capacity has more influence on the hue of the aged spirit that on the corresponding colour intensity. While vanillin has a direct and high correlation with colour intensity (with a value of 0.79 ), this does not imply greater antioxidant capacity (as it can be concluded from its observed negative value of -0.79 ).
Principal component analysis. Figure 3 shows the scores plot from the first two principal components (PCs), obtained with the vanillin concentration, antioxidant capacity and chromatic characteristics as variables, which explain $87.41 \%$ of the variability among the samples. The PCl (62.24\%) was negatively correlated with the majority of variables studied, mainly with the vanillin concentration, phenolic substances, colour intensity and PSI, and positively correlated with the hue value and the antioxidant capacity. The PC2 $(25.17 \%)$ was mainly positively correlated with the vanillin concentration and hue, and negatively with the concentration of phenolic substances.

Four groups of samples plotted on the plane defined by the two first PCs can be identified (Figure 1). Samples from group 1 (MGM, FCM, AGM and ACM) were better characterised by a high-hue value and low concentration of PS and a low PSI. In contrast, samples included in the group 2 (FGL, FCL, FCU and FGU) were mainly correlated with a high-antioxidant capacity. Group 3 (FCH and FGH) was characterised by the presence of vanillin. Group 4 was formed only by FGM and was not characterised by any of the parameters evaluated.

The PCA analysis clearly showed a good separation of the accelerated aged spirits according to the toast level with independence of the fragment size of the oak (chips or granules) and the origin (French or American).

\section{Conclusions}

The independent variables studied in the Box-Behnken experimental design, ethanol concentration and concentration of oak chips were influential in the maceration process. In all dependent variables, except whiskey lactone for which the ethanol concentration was the most important variable, the concentration of oak chips showed the greatest effect. In general, the contact time between the oak and the distillate did not have significant effect on the corresponding values of the parameters evaluated.

The characteristics of the oak fragments that provided the best properties to the distillates were medium toast French oak granules.

In general, high toast-oak fragments provide greater colour intensity in the accelerated aged spirits but reduce the antioxidant capacity of the corresponding beverage. PCA showed a 
Table 4. Pearson correlation matrix among colour parameters, antioxidant activity and phenolic substances.

\begin{tabular}{|c|c|c|c|c|c|}
\hline Variables & Hue & $\begin{array}{c}\text { Antioxidant } \\
\text { capacity }\end{array}$ & $\begin{array}{c}\text { Phenolic } \\
\text { substances index }\end{array}$ & $\begin{array}{c}\text { Phenolic } \\
\text { substances }\end{array}$ & Vanillin \\
\hline Colour intensity & -0.36 & -0.97 & 0.62 & 0.39 & 0.79 \\
\hline Hue & 1 & 0.39 & -0.69 & -0.67 & -0.20 \\
\hline Antioxidant capacity & & 1 & -0.58 & -0.43 & -0.79 \\
\hline Phenolic substances index & & & 1 & 0.79 & 0.30 \\
\hline Phenolic substances & & & & 1 & 0.08 \\
\hline
\end{tabular}

High correlations (upper than \pm 0.6 ) are shown in bold.

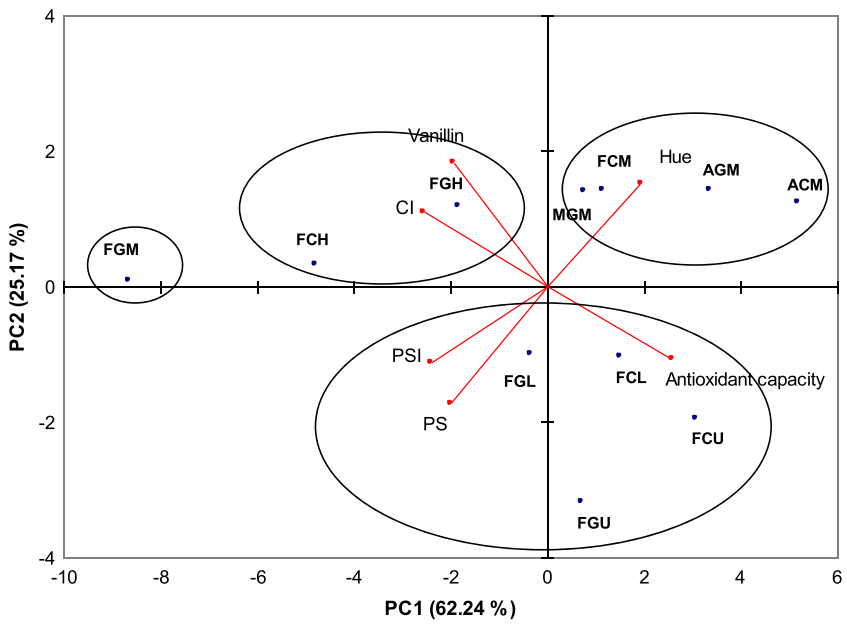

Figure 3. Principal component analysis for the experimental accelerated ageing process based on the mean values of all parameters evaluated. Code: $F$, French oak; A, American oak; M, mixture of French and American oak; G, granules; C, chips; U, untoasted; L, light toast; $M$, medium toast; $H$, heavy toast; PS, phenolic substances; PSI, phenolic substances index; Cl, colour intensity.

good separation of the accelerated aged spirits according to the toast level with independence of the size and origin of the oak fragments.

It should be pointed that these results were obtained on a micro-scale, and they should be tested on an industrial scale. In essence, the value of this work is a starting point that identifies the critical parameters affecting the quality of distillates, thereby minimising the number of experiments required on an industrial scale.

\section{Acknowledgements}

We are grateful to the Spanish Ministry of Economy and Competitiveness for the financial support of this work (project CTQ2015-71436-C2-1-R), which has partial financial support from the FEDER funds of the European Union and to Laffort for providing the samples of oak fragments. Dr José Manuel Salgado was supported by the grant SFRH/BPD/84440/2012 from Fundação para a Ciência e Tecnologia-FCT, Portugal.

\section{References}

Arapitsas, P., Antonopoulos, A., Stefanou, E. and Dourtoglou, V.G. (2004) Artificial aging of wines using oak chips. Food Chemistry 86, 563-570.

Bautista-Ortín, A.B., Lencina, A.G., Cano-López, M., Pardo-Mínguez, F., López-Roca, J.M. and Gómez-Plaza, E. (2008) The use of oak chips during the ageing of a red wine in stainless steel tanks or used barrels: effect of the contact time and size of the oak chips on aroma compounds. Australian Journal of Grape and Wine Research 14, 63-70.
Caldeira, I., Belchior, A.P., Clímaco, M.C. and Bruno de Sousa, R. (2002) Aroma profile of Portuguese brandies aged in chestnut and oak woods. Analytica Chimica Acta 458, 55-62.

Caldeira, I., Mateus, A.M. and Belchior, A.P. (2006) Flavour and odour profile modifications during the first five years of Lourinhã brandy maturation on different wooden barrels. Analytica Chimica Acta 563, 264-273.

Caldeira, I., Bruno de Sousa, R., Belchior, A.P. and Clímaco, M.C. (2008) A sensory and chemical approach to the aroma of wooden aged Lourinhã wine brandy. Ciência e Técnica Vitivinícola 23, 97-110.

Caldeira, I., Anjos, O., Portal, V., Belchior, A.P. and Canas, S. (2010) Sensory and chemical modifications of wine-brandy aged with chestnut and oak wood fragments in comparison to wooden barrels. Analytica Chimica Acta 66, 43-52.

Canas, S., Belchior, A.P., Mateus, A.M., Spranger, M.I. and Bruno-deSousa, R. (2002) Kinetics of impregnation/evaporation and release of phenolic compounds from wood to brandy in experimental model. Ciência e Técnica Vitivinícola 17, 1-14.

Canas, S., Casanova, V. and Belchior, A.P. (2008) Antioxidant activity and phenolic content of Portuguese wine aged brandies. Journal of Food Composition and Analysis 21, 626-633.

Canas, S., Caldeira, I. and Belchior, A.P. (2009) Comparison of alternative systems for the ageing of wine brandy. Wood shape and wood botanical species effect. Ciência e Técnica Vitivinícola 24, 91-99.

Canas, S., Caldeira, I. and Belchior, A.P. (2013) Extraction/oxidation kinetics of low molecular weight compounds in wine brandy resulting from different ageing technologies. Food Chemistry 138, 2460-2467.

Cano-López, M., Bautista-Ortín, A.B., Pardo-Mínguez, F., López-Roca, J.M. and Gómez-Plaza, E. (2008) Sensory descriptive analysis of a red wine aged with oak chips in stainless steel tanks or used barrels: effect of the contact time and size of the oak chips. Journal of Food Quality 31, 645-660.

Combs, G.F. Jr. (1991) The vitamins: fundamental aspects in nutrition and health. American Journal of Clinical Nutrition 53, 755-763.

Cruz, S., Canas, S. and Belchior, A.P. (2013) Effect of ageing system and time on the quality of wine brandy aged at industrial-scale. Ciencia e Tecnica Vitivinicola 27, 83-93.

De Aquino, F.W.B., Rodrigues, S., do Nascimento, R.F. and Casimiro, A. R.S. (2006) Simultaneous determination of aging markers in sugar cane spirits. Food Chemistry 98, 569-574.

Engelhardt, U. (2001) The health effects of tea and tea components Critical Review in Food Science and Nutrition 41(suppl), 398-399.

European Commission (2005) Council Regulation (EC) No 2165/2005 of 20 December 2005 amending Regulation (EC) No. 1493/1999 on the common organisation of the market in wine. Official Journal of the European Union L 345, 1-4.

Fan, W., Xu, Y. and Yu, A. (2006) Influence of oak chips geographical origin, toast level, dosage and aging time on volatile compounds of apple cider. Journal of the Institute of Brewing 112, 255-263.

Fernández de Simón, B., Cadahía, E., Del Álamo, M. and Nevares, I. (2010) Effect of size, seasoning and toasting in the volatile compounds in toasted oak wood and in a red wine treated with them. Analytica Chimica Acta 660, 211-220.

Gimenez Martinez, R., Lopez Garcia de la Sevrana, H., Villalon Mir, M., Quesada Granados, J. and Lopez Martinez, M.C. (1996) Influence of wood heat treatment, temperature and maceration time on vanillin, syringaldehyde and gallic acid. Contents in oak wood and wine spirit mixture. American Journal of Enology and Viticulture $47,441-446$ 
Glories, Y. (1984) La couleur des vins rouges. Mésure origine et interprétation. Connaissance de la Vigne et du Vin 18, 252-254.

Goldberg, D.M., Hoffman, B., Yang, J. and Soleas, G.J. (1999) Phenolic constituents, furans, and total antioxidant status of distilled spirits. Journal of Agricultural and Food Chemistry 47, 3978-3985.

Granato, D. and Masson, M.L. (2010) Instrumental color and sensory acceptance of soy-based emulsions: a response surface approach. Food Science and Technology 30, 1090-1096.

Halliwell, B., Gutteridge, J. and Cross, C.E. (1992) Free radicals, antioxidants, and human disease: where are we now? The Journal of Laboratory and Clinical Medicine 119, 598-620.

Jánacová, A., Sádecká, J., Kohajdová, Z. and Spanik, I. (2008) The identification of aroma-active compounds in Slovak brandies using GC-sniffing, GC-MS and sensory evaluation. Chomatographia 67, 113-121

Jordão, A.M., Correia, A.C., DelCampo, R. and González SanJosé, M.L. (2012) Antioxidant capacity, scavenger activity, and ellagitannins content from commercial oak pieces used in winemaking. European Food Research and Technology 235, 817-825.

Léauté, R., Mosedale, J.R., Mourgues, J. and Puech, J.-L. (1998) Barrique et vieillissement des eaux-de-vie. Flanzy, C., ed. Oenologie fondements scientifiques ettechnologiques. Collection Sciences et Techniques Agroalimentaires (Lavoisier: Paris, France) pp. 1110-1142.

Lee, K.Y.M., Paterson, A., Piggott, J.R. and Richardson, G.D. (2000) Perception of whisky flavour reference compounds by Scottish distillers. Journal of the Institute of Brewing 106, 203-208.

Official Diary from Galicia (2012) Council Regulation 2012/1/16 on the definition, description and presentation of Geographical Indications Orujo, spirits herbs, herbal liqueur and coffee liqueur from Galicia. Galician Official Paper 10, 2516-2546.

Organisation Internationale de la Vigne et du Vin. (2005). Morceaux de bois de chêne. Résolution $N^{\circ} 3$ du 20 Juillet 2005, OENO 3/2005 (Organisation Internationale de la Vigne et du Vin: Paris, France).

Pérez-Coello, M.S., Sanz, J. and Cabezudo, M.D. (1998) Gas chromatographic-mass spectrometric analysis of volatile compounds in oak wood used for ageing of wines and spirits. Chromatographia 47, 427-432.

Pérez-Prieto, L.J., López-Roca, J.M., Martínez-Cutillas, A., Pardo Minguez, F. and Gómez-Plaza, E. (2002) Maturing wines in oak barrels. Effects of origin, volume, and age of the barrel on the wine volatile composition. Journal of Agricultural and Food Chemistry 50, 3272-3276.

Pizarro, C., Rodríguez-Tecedor, S., Esteban-Díez, I., Pérez-Del-Notario, N. and González-Sáiz, J.M. (2014) Experimental design approach to evaluate the impact of oak chips and micro-oxygenation on the volatile profile of red wines. Food Chemistry 148, 357-366.

Priyadarsini, K.I., Khopde, S.M., Kumar, S.S. and Mohan, H. (2002) Free radical studies of ellagic acid, a natural phenolic antioxidant. Journal of Agricultural and Food Chemistry 50, 2200-2206.

Quesada Granados, J., Merelo Guervos, J.J., Oliveras López, M.J., González Peñalver, J., Olalla Herrera, M., Blanca Herrera, R. and Lopez Martinez, M.C. (2002) Application of artificial aging techniques to samples of rum and comparison with traditionally aged rums by analysis with artificial neural nets. Journal of Agricultural and Food Chemistry 50, 1470-1477.

Rawson, A., Hossain, M.B., Patras, A., Tuohy, M. and Brunton, N. (2013) Effect of boiling and roasting on the polyacetylene and polyphenol content of fennel (Foeniculum vulgare) bulb. Food Research International 50, 513-518.

Ribéreau-Gayon, P. (1970) Le dosage des composés phénoliques totaux dans les vins rouges. Analytica Chemie 52, 627-631.

Rodríguez Madrera, R., Valles, B.S., García, Y.D., del Valle Argüelles, P. and Lobo, A.P. (2010) Alternative woods for aging distillates-an insight into their phenolic profiles and antioxidant activities. Food Science and Biotechnology 19, 1129-1 134.

Rodríguez Madrera, R., García Hevia, A. and Suárez Valles, B. (2013) Comparative study of two aging systems for cider brandy making. Changes in chemical composition. LWT--Food Science and Technology 54, 513-520.

Rodríguez-Solana, R., Rodríguez, N., Domínguez, J.M. and Cortés, S. (2012) Characterization by chemical and sensory analysis of commercial grape marc distillate (Orujo) aged in oak wood. Journal of the Institute of Brewing 118, 205-212.

Rodríguez-Solana, R., Salgado, J.M., Domínguez, J.M. and Cortés-Diéguez, S. (2014a) Characterization of fennel extracts and quantification of estragole: optimization and comparison of accelerated solvent extraction and soxhlet techniques. Industrial Crops and Products 52, 528-536.

Rodríguez-Solana, R., Salgado, J.M., Domínguez, J.M. and Cortés-Diéguez, S. (2014b) Estragole quantity optimization from fennel seeds by supercritical fluid (carbon dioxide-methanol) extraction using a Box-Behnken design. Characterization of fennel extracts. Industrial Crops and Products 60, 186-192.

Rodríguez-Solana, R., Salgado, J.M., Domínguez, J.M. and Cortés-Diéguez, S. (2014c) First approach to the analytical characterization of barrel-aged grape marc distillates using phenolic compounds and colour parameters. Food Technology and Biotechnology 52, 391-402.

Schwarz, M., Rodríguez, M.C., Sánchez, M., Guillén, D.A. and Barroso, C.G. (2014) Development of an accelerated aging method for Brandy. LWT--Food Science and Technology 59, 108-1 14.

Singleton, V.L. (1995) Maturation of wines and spirits: comparisons, facts, and hypothesis. American Journal of Enology and Viticulture 46, 98-1 15 .

Singleton, V.L. and Rossi, J.A. (1965) Colorimetry of total phenolics with phosphomolybdic-phosphotungstic acid reagents. American Journal of Enology and Viticulture 16, 144-158.

Singleton, V.L., Orthofer, R. and Lamuela-Raventós, R.M. (1998) Analysis of total phenols and other oxidation substrates and antioxidants by means of Folin-Ciocalteu reagent. Methods in Enzymology 299, $152-178$.

Soares, B., Garcia, R., Costa Freitas, A.M. and Cabrita, M.J. (2012) Phenolic compounds released from oak, cherry, chestnut and robinia chips into a synthetic wine: influence of toasting level. Ciencia e Tecnica Vitivinicola 27, 17-26.

Sroka, Z. and Cisowski, W. (2003) Hydrogen peroxide scavenging, antioxidant and antiradical activity of some phenolic acids. Food and Chemical Toxicology 41, 753-758.

Umar, A., Boisseau, M., Segur, M.-C., Begaud, B. and Moore, N. (2003) Effect of age of Armagnac extract and duration of treatment on antithrombotic effects in a rat thrombosis model. Thrombosis Research 111, 185-189.

Vinson, J.A., Su, X., Zubik, L. and Bose, P. (2001) Phenol antioxidant quantity and quality in foods: fruits. Journal of Agricultural and Food Chemistry 49, 5315-5321.

Wang, Y. and Dai, H. (2012) Optimization of fermentation process for apple wine by response surface methodology. China Brewing 8 , 19-23.

Yilmaz, Y. and Toledo, R.T. (2006) Oxygen radical absorbance capacities of grape/wine industry byproducts and effect of solvent type on extraction of grape seed polyphenols. Journal of Food Composition and Analysis 19, 41-44.

Zhang, J., Zhang, Y., Han, S., Li, X. and Zeng, C. (2011) Optimization of the fermentation of cider vinegar by mixed yeast fermentation and response surface method. Liquor-Making Science $\&$ Technology $\mathbf{6}$, 38-41.

\section{Manuscript received: 14 April 2015}

Revised manuscript received: 03 September 2015

Accepted: 03 September 2015

\section{Supporting information}

Additional Supporting Information may be found in the online version of this article at the publisher's web-site: http://onlinelibrary.wiley.com/doi/10.1111/ajgw.12249/abstract

Figure S1. Scheme of the experimental accelerated ageing process for grape marc distillates.

Table S1. Characteristics of the oak wood used for the accelerated aging.

Table S2. Levels of independent variables and dimensionless coded variables definition (xi). 